\title{
La cultura como dinámica: el arte cartográfico de Miguel Covarrubias
}

\section{Culture as a Dinamic: Miguel Covarrubias' Cartographic Art}

Artículo recibido el 22 de abril de 20I8; devuelto para revisión el I6 de enero de 20I9; aceptado el 23 de febrero de 2019; http://dx.doi.org/Io.2220I/iie.18703062e.2019.monoI.27II.

Mónica Ramírez Bernal Investigadora independiente; mnica.ramírez@gmail.com; http://orcid. org/0000-0002-0653-974x.

Líneas de investigación Cultura visual en el siglo xx; geografía y arte.

Lines of research Visual culture of the twentieth century; geography and art.

Publicación más relevante El océano como paisaje. Pageant of the Pacific: la serie de mapas murales de Miguel Covarrubias (México: Universidad Nacional Autónoma de México-Instituto de Geografía, 20I8).

Resumen Miguel Covarrubias formó parte de un grupo de artistas, como Roberto Montenegro, Antonio Ruiz y Carlos Mérida, que se preocuparon por profundizar en el estudio y el diseño de mapas. Ya sea en formato mural o como ilustraciones de un libro, Covarrubias cuenta con un acervo considerable de mapas artísticos que revelan el atento conocimiento que tenía de las tradiciones cartográficas. El propósito de este artículo es desentrañar y explorar la manera en la que Miguel Covarrubias trasladaba ideas propias de los estudios sobre el arte para resolver algún problema geográfico. Para lograrlo, tomaré como caso de estudio algunos mapas de Covarrubias para relacionarlos con las ideas contemporáneas acerca de la geografía cultural. Quienes se dedicaban a su estudio reconocían que una de las principales cualidades de esta rama de la geografía era la facilidad con la que quienes la practicaban podían transitar entre la antropología, la arqueología o la historia y los asuntos eminentemente geográficos sin importar las fronteras disciplinares.

Palabras clave Geografía cultural; cartografía; océano Pacífico; morfología; mapas murales.

Abstract Miguel Covarrubias was part of a group of artist —along with Roberto Montenegro, Antonio Ruiz, and Carlos Mérida - that took interest in the study and design of maps. Either as murals or as book illustrations, 
Covarrubias made a large collection of artistic maps that reveal his deep knowledge of the cartographic traditions. This paper aims to unveil and explore Covarrubias' way of translating his ideas about art studies in order to solve a geographic problem. I will take some maps as case studies, and relate them with contemporary ideas about cultural geography. Those who devoted their attention to this kind of studies recognized that one could easily move between anthropology, archeology, history, and geography subjects without restrictions or disciplinary boundaries.

Keywords Cultural geography; cartography; Pacific Ocean; morphology; mural maps. 
https://doi.org/10.22201/iie.18703062e.2019.mono1.2711

\author{
MÓNICA RAMÍREZ BERNAL
}

\title{
La cultura como dinámica: el arte cartográfico de Miguel Covarrubias
}

Enséñame a un geógrafo que no necesite [mapas] constantemente, que no los quiera cerca de él, y dudaré si ha hecho una elección correcta de vida.

CARL SAUER, Education of a geographer, 1956

M

iguel Covarrubias dedicó buena parte de su vida a hacer mapas. Tal fue su predilección hacia la cartografía que pocos eran los trabajos que emprendiera en los que no se incluyera, al menos, un mapa dibujado por él. Ya fuera en forma de murales o como ilustraciones de un libro, el arte cartográfico de Covarrubias muestra a un artista que encontró los elementos necesarios para representar la dinámica entre los territorios y las culturas que se desarrollan en ellos. En sus mapas hay cierta precisión en el uso de las proyecciones, un cuidadoso delineado de los territorios, la presencia de elementos gráficos como rosas náuticas y cartelas, además de una informada elección de las figuras, lo cual demuestra el amplio conocimiento de la historia de la cartografía con el que contaba. Covarrubias coleccionaba, veía y dibujaba mapas como quien reúne un acervo que le servirá para transmitir su visión acerca del mundo.

Hacia finales de la década de los años treinta el artista realizó una serie de seis mapas murales conocidos como Pageant of the Pacific para decorar los muros del Pacific House, el edificio temático de la Golden Gate International Exposition (GGIE) (San Francisco, California, I939-I940). Gracias a esta expe- 
riencia tuvo contacto con algunos miembros de la Universidad de California en Berkeley, lo que lo llevó a conocer los preceptos de la llamada geografía cultural: "Las fronteras comunes entre geografía, antropología, arqueología, ecología e historia nunca han estado, y sin duda nunca estarán claramente definidas. Esperamos que los geógrafos culturales y todos aquellos que comparten sus intereses continúen cruzando estas fronteras". I Dentro de un contexto en donde las fronteras estaban ampliamente difuminadas, la participación de un artista como Covarrubias no solamente sería muy bien recibida sino que se le consideraría necesaria, revelando de paso el carácter eminentemente visual de la geografía.

\section{Cartografía artística}

A principios de agosto de 1938, cuando Miguel Covarrubias llegó a la bahía de San Francisco para trabajar en el diseño de los mapas murales, las placas de masonite pegadas con cemento que servirían como soporte ya estaban armadas, la proyección cartográfica —-mostrando al océano Pacífico en el centrohabía sido elegida y la investigación acerca de las figuras que se incluirían en los mapas había comenzado. Para estas labores se designó a un grupo de antropólogos y geógrafos, dirigidos por los profesores Alfred L. Kroeber, Carl O. Sauer y Walter Goldschmidt. ${ }^{2}$ Por otro lado, el arquitecto y museógrafo Phillip N. Youtz, antiguo director del Brooklyn Museum y presidente de la American Federation of Arts, había sido nombrado consultor y director de las exposiciones que se albergarían dentro del edificio de Pacific House.

Los seis mapas de Pacific House ilustraron los siguientes temas: I. Peoples of the Pacific, 2. Flora and Fauna of the Pacific, 3. Art Forms of the Pacific, 4. Economy of the Pacific, 5. Native Dwellings of the Pacific Area, y 6. Native Means of Transportation, Pacific Area. Las soluciones finales que Covarrubias

I. "The common frontiers of geography, anthropology, archeology, ecology, and history have never been and doubtless never will be sharply defined. Let us hope that cultural geographers and all who share their interests will continue to move across these frontiers", en P. L. Wagner y M. W. Mikesell, Readings in Cultural Geography (Chicago: The University of Chicago Press, I96I), VIII.

2. Aunque de manera indirecta también estaría involucrado en la realización de los murales René D'Harnoncourt, quien en ese momento estaba organizando la exposición Indian Art of the United States and Alaska, montada en el edificio federal de la GGIE, esta exposición formó parte de un proyecto del Indian Arts and Crafts Board del Departamento del Interior del Gobierno de Estados Unidos. 
les dio a los mapas hacen que los murales sean bastante diferentes entre sí. Sin embargo, lo que comparten es el delineado principal de los continentes y del área oceánica del Pacífico. Para realizar el mapa que funcionaría como base para los murales, Youtz había contactado un par de meses antes al geógrafo Carl O. Sauer, quien describe el encuentro:

[Youtz] Se puso en contacto con nosotros porque quería mapas del Pacífico. Entonces, diseñamos, utilizando dos proyecciones diferentes, mapas base del océano. Éstas van a ser reproducidas como una serie de murales que formarán el motivo decorativo dominante del edificio, además van a ser ejecutados con la finalidad de mostrar la distribución de algunos fenómenos culturales y físicos —una especie de atlas mural, por así decirlo. ${ }^{3}$

De las dos proyecciones diseñadas por Sauer se escogió la de Van der Grinten (fig. I), la cual se hizo a finales del siglo xix a partir de la combinación de las de Mercator y Mollweide. La finalidad era representar la superficie de la tierra en un solo plano circular, sustituyendo así la imagen en dos hemisferios. ${ }^{4}$ En las proyecciones cilíndricas anteriores a la de Van der Grinten los meridianos se acomodaban de manera paralela; en lugar de hacer que éstos convergieran en la medida en que se acercaban a los polos, como sí pasaría en el diseño de un globo. Esta manera de representar el mapamundi provocaba que los territorios y las distancias se agrandaran desproporcionadamente en la medida en que se encontraban más cercanos a los polos. Al cambiar la proyección se lograba comprender de mejor manera las verdaderas dimensiones del océano Pacífico. 5 El diseño de este mapa se volvió el símbolo de la GGIE. En una fotografía del interior del Pacific House (fig. 2) se ven al fondo dos de los mapas de Covarrubias colgados de los muros. Pero esta toma también permite apreciar

3. "He got in touch with us because he wanted some maps of the Pacific. We designed, on two different projections, base maps of the Pacific. These he is reproducing as a series of murals to form the dominant decorative motif of the house and they will be executed so as to show distribution of a number of physical and cultural phenomena - a sort of mural atlas, as it were", en Carl O. Sauer a H. E. Gregory, I2 de julio de 1938. UC Berkeley-The Bancroft Library, Carl Otwin Sauer Papers.

4. E. A. Reeves, "Van der Grinten's Projection”, The Geographical Journal 24, núm. 6 (diciembre 1904), 670-672.

5. Este tipo de proyección se utilizó tanto por el gobierno estadounidense como por la National Geographic Society, durante la mayor parte del siglo xx. 


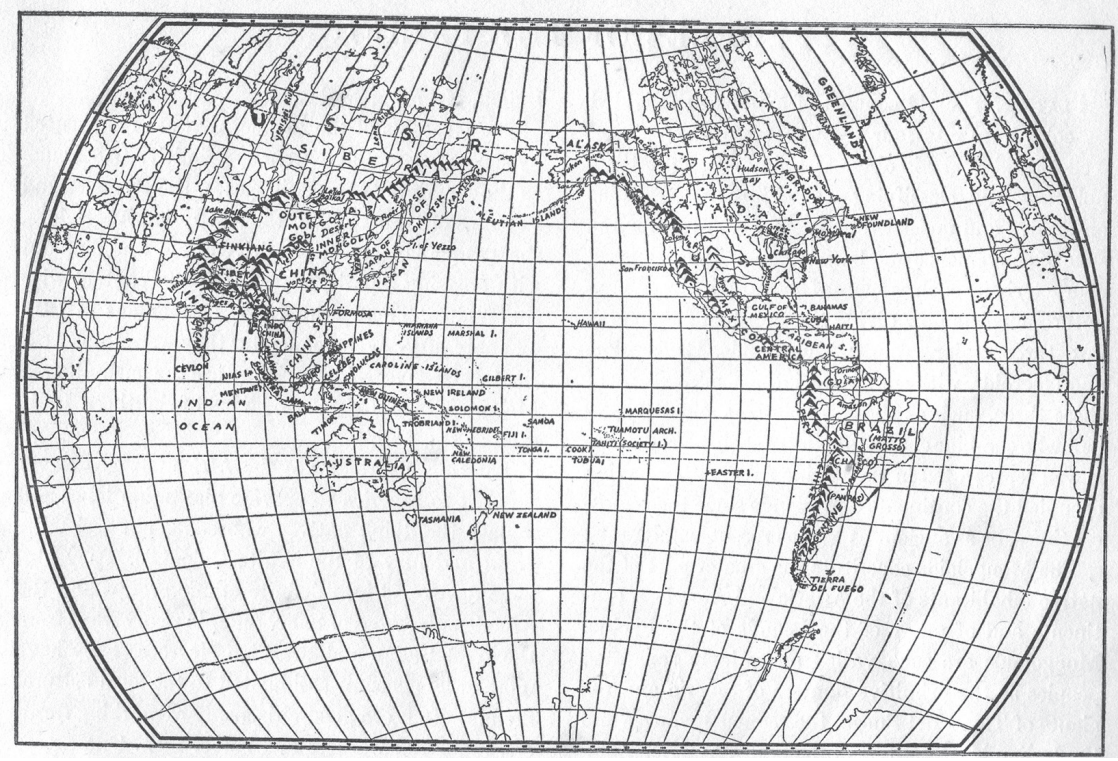

I. Van der Grinten's Projection of the World, 1938. Pacific House, Golden Gate International Exposition.

en primer plano una gran fuente de terracota hecha por el artista Antonio Sotomayor, que ocupaba la parte central del edificio. En ésta también se reproducía el mapa con el océano Pacífico en el centro. La imagen del mapa sería replicada en otras obras de arte, en folletos y carteles a lo largo de toda la feria. En este sentido, el historiador Robert W. Rydell destaca que para esta exposición internacional resultó fundamental exponer sus contenidos aludiendo a conceptos del espacio. ${ }^{6}$ Para lograrlo fue necesario insistir en trazar nuevos mapas y crear nuevas geografías. Por otro lado, Andrew M. Shanken, quien dedicó un libro al análisis de la propuesta arquitectónica de GGIE, asegura que la feria nació, sobre todo, de un imaginario geográfico, que estaba íntimamente relacionado con la intención de pensar al océano Pacífico como un paisaje alterativo para el desarrollo de las relaciones internacionales. En palabras de Shanken: "Si el Pacífico tenía un subtexto, era como un antídoto al mundo Atlántico."7

6. Robert W. Rydell, World of Fairs. The Century-of-Progress Expositions (Chicago: The University of Chicago Press, 1993), 213.

7. "If the Pacific had a subtext, it was as an antidote to the Atlantic world, rather than complicity 


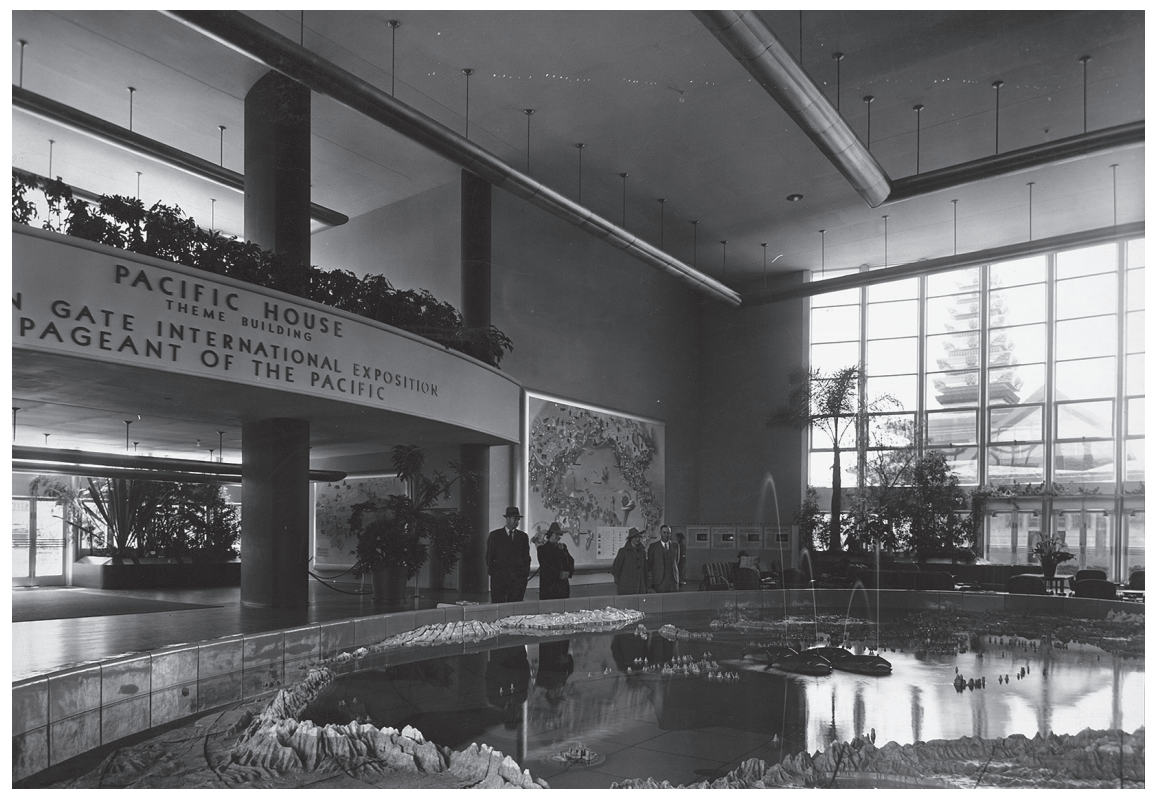

2. Esther Born, Pacific House (view of the interior), ca. 1939. Ernest and Esther Born Collection, Environmental Design Archives, UC Berkeley.

\section{Ojo morfológico}

Los mapas son objetos muy complejos que pueden estudiarse desde diversos puntos de vista. Como lo describe el geógrafo David Woodward en la introducción de una compilación de ensayos que lleva por nombre Art and Cartography, desde la década de los años ochenta los estudiosos de la cartografía se han interesado en realizar investigaciones interdisciplinarias, tarea que ha ocupado tanto a geógrafos como a historiadores del arte. Esto respondía a la conciencia, cada vez mayor, del hecho de que "el arte y la ciencia han coe-

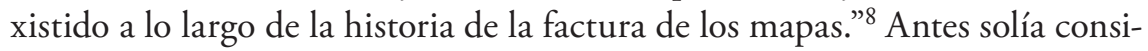
derarse que la historia de los mapas podía dividirse en dos momentos: uno en el que se privilegiaban los elementos pictóricos, mientras que la información

with it", en Andrew M. Shanken, Into the Void Pacific: Building the 1939 San Francisco World's Fair (California: University of California Press, 2014), I9.

8. "Art and science have coexisted throughout the history of mapmaking", en David Woodward, ed., Art and Cartography: Six historical Essays (Chicago: University of Chicago Press, 1987), 2. 
geográfica parecía ser poco precisa y, otro, en el cual la certeza científica sustituyó poco a poco a los elementos pictóricos. Sin embargo, la propuesta de la nueva historia de la cartografía considera no tanto la supuesta separación de las disciplinas, sino la atención en aquellos momentos en los que el arte y la ciencia de hacer mapas se cruzan.

Entonces ¿cuáles fueron las circunstancias y las relaciones que le dieron a la obra de Miguel Covarrubias un carácter especial? Como ya se ha anotado, las cualidades del arte cartográfico de Covarrubias respondían a algunas de las necesidades que se estaban planteando desde la escuela estadounidense de la geografía cultural. Sin embargo, resulta necesario destacar que, además de los temas y las preocupaciones, su labor se relaciona más profundamente con un rasgo metodológico planteado desde los estudios de este grupo de geógrafos dirigidos por Carl O. Sauer.

Sauer fue uno de los geógrafos más importantes del siglo xx, con una influencia decisiva tanto en México como en Latinoamérica. ${ }^{9}$ Durante su trabajo en la Universidad de California formó a una generación de geógrafos que serían conocidos como la Escuela de Berkeley, quienes se distinguían por promover y defender un enfoque histórico y cultural en los estudios de geografía. Sus trabajos surgen como una respuesta a las nociones que había desarrollado la geografía como disciplina en el siglo XIX, dominadas por el positivismo. En contra de estas últimas, Sauer proponía recuperar una visión de la geografía que él había localizado en los trabajos de los autores de la Antigüedad clásica; ${ }^{10}$ sobre todo, en aquellos escritos en los que el paisaje fuera el objeto principal de las reflexiones. La geografía cultural, más que tratarse de una doctrina, implicaba un conjunto de afinidades que compartía un grupo de geógrafos, quienes realizaban sus investigaciones alrededor de una idea general: el hombre como factor prevaleciente, aunque no el único. Por tanto, era apremiante apli-

9. Para un estudio más amplio sobre la relación de la Escuela de Berkeley con Lationamérica véanse Pedro Sergio Urquijo Torres y Gerardo Bocco Verdinelli, "Pensamiento geográfico en América Latina: retrospectiva y balances generales”, Investigaciones Geográficas, Boletín del Instituto de Geografía, núm. 90 (2016); y Pedro S. Urquijo Torres y Paola C. Segundo Métay, "Escuela de Berkeley: aproximación al enfoque geográfico, histórico y ambiental Saueriano", en Geografía e historia ambiental (México: Universidad Nacional Autónoma de México-Centro de Investigaciones en Geografía Ambiental, 2017).

Io. Una de sus referencias serían los escritos de Heródoto de quien, dice, deriva la idea de que la Tierra no solamente es el escenario en donde se desarrolla la vida del hombre, sino que el escenario también tiene vida. 
car una idea de cultura, evidentemente ligada a la antropología, para resolver problemas geográficos: "En esta tradición, la geografía cultural es la aplicación de la idea de cultura a los problemas geográficos". ${ }^{\text {II }}$ Así, se hacía una especie de inversión de los términos: para esta primera generación de geógrafos culturales no era la naturaleza (los factores físicos) la que determinaba al hombre, sino que eran los elementos de la cultura material los que le otorgaban a alguna región su carácter particular.

"Cultural Geography" es uno de los textos fundacionales de Carl O. Sauer que apareció publicado por primera vez en la paradigmática Encyclopedia of Social Sciences. ${ }^{12}$ Según lo expuesto en este ensayo, la observación de campo y la representación cartográfica eran las herramientas más importantes para el geógrafo. Al seguir este principio, el procedimiento típico del geógrafo cultural consistía en realizar una investigación del origen y la distribución de ciertos rasgos culturales, tanto los del pasado (sustentados en la arqueología y en la historia) como los del presente (apoyándose en la antropología y la observación de campo). Una vez hecha esta investigación se rastreaba la distribución de los rasgos sobre un mapa, consiguiendo con ello delimitar el territorio en áreas culturales. Este último concepto se utilizó por antropólogos, arqueólogos y geógrafos por igual. Sin embargo, para Sauer la manera en la que era utilizada por la geografía era más sencilla, por tanto más exacta, ya que su objetivo final era llevar a cabo estudios comparativos entre las distintas áreas culturales:

Se ha considerado que el área cultural geográfica consiste solamente en: las expresiones de la ocupación del hombre sobre la tierra, la recopilación cultural que registra toda la extensión del uso que le da el hombre a la superficie o [...] los rasgos visibles, expresivos y extensivos de la presencia humana. Todos estos datos son mapeados por el geógrafo en cuanto a su distribución. Después son agrupados según sus asociaciones genéticas para rastrear su origen y síntesis, para, finalmente, obtener un sistema comparativo de áreas culturales. ${ }^{13}$

II. "In this tradition, cultural geography is the application of the idea of culture to geographic problems", en M.W. Mikesell, "General Introduction. The Themes of Cultural Geography", en Readings in Cultural Geography (Chicago: The University of Chicago Press, 196I) I.

I2. Editada en 193I por the Macmillan Company de Nueva York.

I3. "The geographic culture area is taken to consist only of the expressions of man's tenure of the land, the culture assemblage which records the full measure of man's utilization of the surface or $[\ldots]$ the visible, areally extensive and expressive features of man's presence. These the geographer maps as to distribution, groups as to genetic association, traces as to origin and synthesizes into 


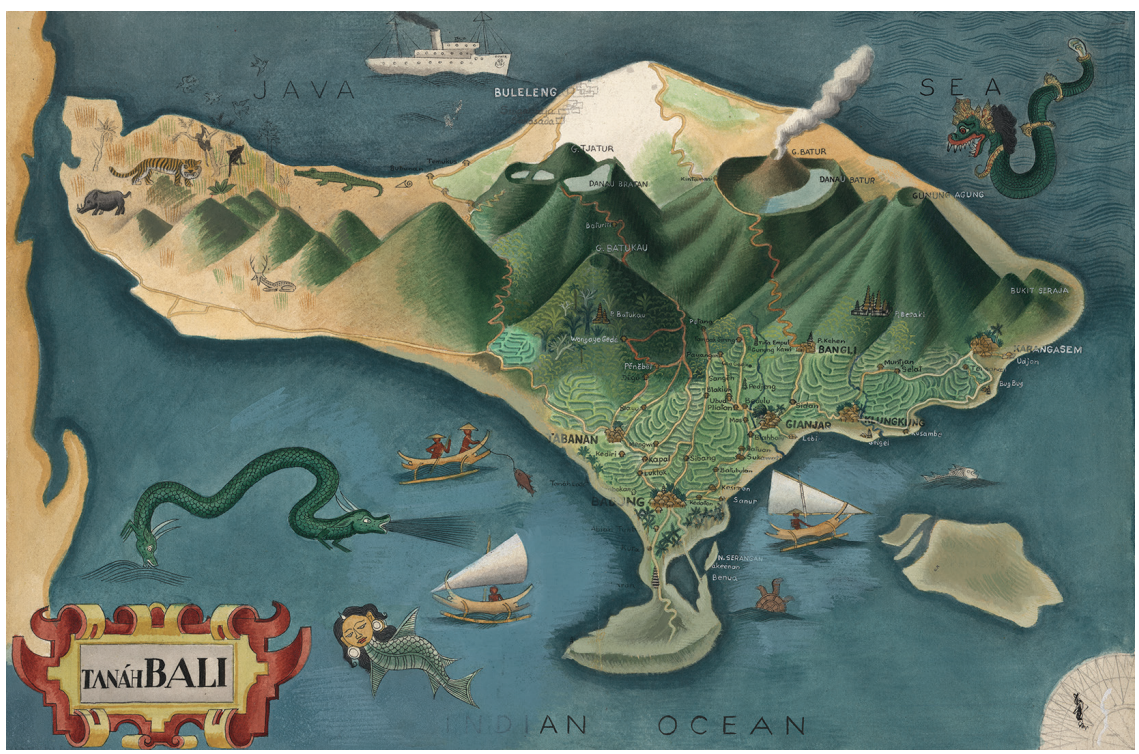

3. Miguel Covarrubias, Tanah Bali, ca. 1937. Prints and Photographs Division. Photograph. Retrieved from the Library of Congress, Washington, D.C.

Antes de entrar en contacto con este grupo de geógrafos, Covarrubias ya realizaba mapas en los que recopilaba imágenes para expresar el carácter de una región. Por ejemplo, en el mapa Tanah Bali (fig. 3), que pintó alrededor de 1937, se observa una variedad de figuras que dan cuenta de algunos rasgos culturales cuidadosamente colocados sobre el territorio. Es el caso de los tradicionales cultivos de arroz por medio de terrazas colocadas en el sur de la isla, en donde además se señalan los nombres de varias poblaciones y aparecen templos y algunas casas. Alrededor de esta zona, pero en el océano, se ve a un grupo de hombres pescando a bordo de embarcaciones balinesas; estas figuras contrastan con el barco turista que se encuentra en la parte superior del mapa y que se aproxima con velocidad a la isla. Hacia el oeste de la isla, se distingue a un grupo de animales, entre ellos un cocodrilo y un tigre, relacionados con elementos de la religión local. Pero, lo que le da un carácter especial a esta cartografía son los personajes de la mitología balinesa que flotan alrededor de la isla, como es el caso de la serpiente Antaboga en la esquina superior derecha.

a comparative system of culture areas", en Carl O. Sauer, "Cultural Geography", en Readings in Cultural Geography (Chicago: The University of Chicago Press, 196I), 33. 


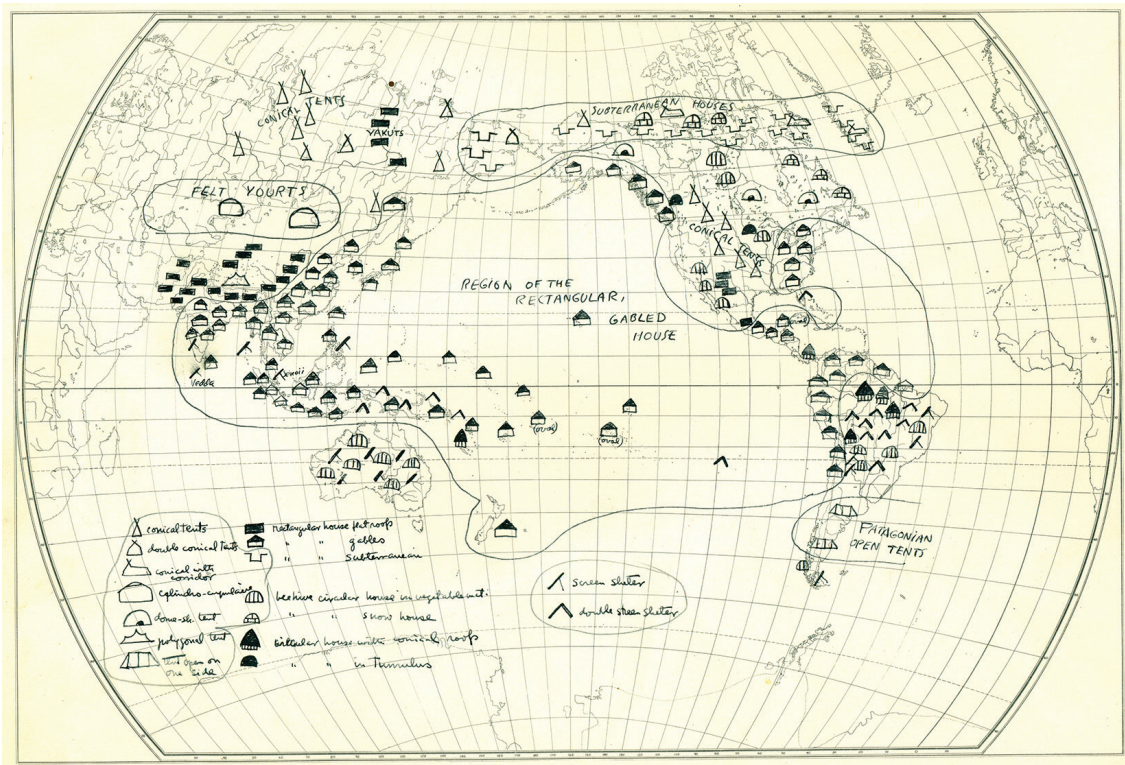

4. Miguel Covarrubias, Native Dwellings of the Pacific Area (boceto), ca. 1938. No. Catálogo: 741o. Archivo Miguel Covarrubias. Sala de Archivos y Colecciones Especiales, Dirección de Bibliotecas, Universidad de las Américas, Puebla.

Sin embargo, no fue si no hasta 1938 cuando Covarrubias recurrió a los mapas como ejercicios que seguirían más cercanamente el procedimiento que en líneas anteriores describía Sauer. Si se analiza, por ejemplo, uno de los bocetos trazados por el artista para el mapa mural Native Dwellings of the Pacific Area (fig. 4), es posible observar un estudio de los diferentes tipos de construcciones que erigían las culturas que habitaban alrededor de la cuenca del Pacífico. Covarrubias colocó sobre el territorio las figuras de las construcciones y, en la parte inferior izquierda, las agrupó en un listado basado en la proyección hecha por los estudiantes de geografía de la Universidad. Una vez distribuidas sobre el mapa intentó delimitar áreas culturales en donde, al notar cierta coincidencia, podría existir una región con características particulares que la distinguieran del resto. Es así como se establece una comparación entre las casas subterráneas, las tiendas con forma cónica, las casas rectangulares con tejados a dos aguas, entre otras.

En los mapas del Pacífico de Covarrubias se combinaba por igual la proyección geométrica de una región del mundo, con las imágenes creadas por él 
de los habitantes, la flora, la fauna, la industria, la arquitectura y los medios de transporte, que en conjunto lograban transmitir el carácter de la región. Para definir qué imágenes y dónde iban a estar colocadas, el artista siguió el procedimiento cartográfico planteado por la geografía cultural. No se debe pasar por alto que al comenzar a estudiar los principios del difusionismo antropológico, una de las finalidades de Covarrubias era demostrar que existía una serie de conexiones entre las culturas que rodeaban a la cuenca del Pacífico. Es decir, la convivencia con antropólogos y geógrafos le permitía explorar las posibilidades de que en la distribución de ciertos rasgos de las distintas culturas del Pacífico existiera un orden y correspondencias que solamente por medio de un mapa podrían evidenciarse.

Gracias a esta generación de la Escuela de Berkeley, el mapa fue reconocido como la expresión más apropiada para plantear los problemas geográficos y el medio ideal parar buscar sus respuestas. De esta manera, destacaban el carácter eminentemente gráfico y visual de sus investigaciones. Pero, los mapas eran más que herramientas de estudio. Para Carl Sauer además de ser objetos visuales complejos, eran detonadores de múltiples experiencias. Se refiere a ellos en el texto "La educación del geógrafo": "Los mapas rompen nuestras inhibiciones, estimulan nuestras glándulas, remueven nuestra imaginación, sueltan nuestras lenguas. Los mapas hablan a través de las barreras del lenguaje; a veces se asegura que son el verdadero lenguaje de la geografía." " Esta cita habla del importante lugar que la cartografía tiene en la historia de la geografía. $\mathrm{Si}$ bien, en palabras de Denis Cosgrove, ésta no es el único medio para expresar el conocimiento geográfico: "La descripción geográfica, que cumple con la tarea de interrogar, sintetizar y representar la diversidad de los ambientes, lugares y habitantes, tradicionalmente ha buscado presentar a su audiencia ricas y atractivas imágenes visuales. El mapa es una manera poderosa de lograr esta meta." Is

I4. "Maps break down our inhibitions, stimulate our glandes, stir our imagination, loosen our tongues. The map speaks across the barriers of language; it is sometimes claimed as the language of geography", en Carl O. Sauer, "The Education of the Geographer," Annals of the Association of American Geographers 43, núm. 3 (septiembre de 1956): 289.

I5. "Geographic description, which performs the task of interrogating, synthesizing and representing the diversity of environments, places and people, has traditionally sought to present its audience with rich and compelling visual images. The map is one powerful way of achieving these goals", en Denis Cosgrove, Geography and Vision: Seeing, Imaginig and Representing the World (Londres: I.B. Tauris, 2008), 6. 
Sauer, gracias a sus conocidas reflexiones sobre el paisaje, específicamente lo que él llamaba el paisaje cultural, es decir, la cultura material y los rasgos de la naturaleza que habían sido afectados por ésta, aseguraba que un buen geógrafo por necesidad tenía que contar con un "ojo morfológico". Sus funciones deberían ir más allá de los análisis puramente cuantitativos en los que antes se basaba la ciencia de la geografía. Este "ojo morfológico" se definía de la siguiente manera: "como una espontánea y crítica atención a las formas y los patrones" ${ }^{16}$ o "como una innata aptitud para registrar las diferencias y similitudes, sumada a una curiosidad dispuesta y a una reflexión del significado tanto de los parecidos como de las diferencias." ${ }^{77}$ La morfología era el concepto que relacionaba a la geografía con las ciencias naturales desarrolladas en el siglo XIX.

Covarrubias comprendió que el carácter visual de la geografía iba en dos sentidos: por un lado, como un artista reconoció que los mapas tendrían que ser imágenes lo suficientemente estimulantes como para convertirse en el medio privilegiado para la explicación, la imaginación y el entendimiento de las culturas y los territorios que se querían representar; pero también, en el hecho de que la persona que los realizara tendría que tener la capacidad de reconocer, en la multiplicidad de formas, aquellas que fueran lo suficientemente significativas como para relacionarse con otras, trazar secuencias y encontrar patrones. Al construir explicaciones a partir de la observación, la pintura y el dibujo, Covarrubias estaba plenamente consciente de que la visualidad era una herramienta privilegiada para obtener conocimiento. Gracias a sus mapas y a su relación con la Escuela de Berkeley demostró que, incluso en el siglo xx, para convertirse en un geógrafo era fundamental ser también un artista.

\section{Topografía del arte}

Uno de los alumnos más destacados de Sauer fue John Leighly, quien se incorporó gracias a él al grupo de académicos de la Universidad de Berkeley para impartir las clases de cartografía. En 1937, una fecha muy cercana a la creación de los mapas del Pacífico, Leighly presentó un texto a la Asociación de Geógrafos

I6. "a spontaneous and critical attention to form and pattern", en Sauer, "The Education of the Geographer," 290, textos originales en inglés.

17. "An innate aptitude to register on differences and similarities is joined to a ready curiosity and reflection on the meaning of likeness and unlikeness", en Sauer, "The Education of the Geographer," 290, textos originales en inglés. 
Americanos: Sobre algunos comentarios al método geográfico contemporáneo. En éste expone cómo, de acuerdo con algunos de los principales preceptos de la geografía cultural, el geógrafo tendría que abocarse a la descripción sistemática de regiones. Pero Leighly se encontraba preocupado por la metodología - o más bien por la falta de una metodología clara - para que los miembros de la academia estadounidense de geógrafos pudieran realizar sus descripciones.

Aunque él se refería a las descripciones escritas, no en específico a los mapas, no es casual que fuera precisamente el encargado de impartir las clases de cartografía quien hiciera las siguientes anotaciones. Al enfrentarse a la multitud de hechos y rasgos culturales disponibles para las descripciones era necesario hacer una selección de ellos y sintetizarlos para así presentar un panorama relativamente complejo de la región. La elección de estos rasgos era por completo subjetiva y la responsabilidad descansaba en el geógrafo. Sin embargo, Leighly se preguntaba si “¿podría haber una ciencia que operara por la síntesis de hechos heterogéneos arbitrariamente seleccionados?"I8 Él mismo responde:

Solamente hay un modo intelectualmente respetable de aprehensión y de expresión en el cual hay una síntesis de hechos heterogéneos y arbitrarios: el artístico. Su autoridad, la base de cualquier validez que sus productos posean, se le otorga por la habilidad y la integridad intelectual del artista. Esta integridad y habilidad elevan al arte por encima del estatus del culto. Su subjetividad lo distingue de las ciencias. Pueden existir cultos artísticos y técnicas artísticas derivadas de la ciencia. Pero esas relaciones no son esenciales: el trabajo del artista continúa siendo la vía que encamina la habilidad técnica de las experiencias percibidas subjetivamente y que son arbitrariamente seleccionadas. En el estado actual de la ciencia, y en el estado futuro que esperamos se pueda desarrollar, el científico debe de proceder por análisis, y su alcance será mas profundo entre más detenido sea. El artista es el sintetizador de fenómenos; hasta donde podemos apreciar, el único que puede reunir hechos intelectualmente inconmensurables para formar un todo conceptualmente satisfactorio y comprensible. ${ }^{19}$

I8. "Can there be a science that operates by the "synthesis" of arbitrary selected heterogeneous facts?", en John Leighly, "Some Comments in Contemporary Geographic Method," Annals of the Association of American Geographers 27, núm. 3 (septiembre de 1937): 131.

19. "There is only one intellectually respectable mode of apprehension and expression in which there is synthesis of heterogeneous and arbitrarily selected facts: the artistic. Its sanction, the basis of whatever validity its products possess, is given by the skill and intellectual integrity of the artist alone. That skill and integrity raise art above the status of a cult. Its subjectivity distinguishes it 
Leighly encontraba en el arte, tanto en las imágenes artísticas como en las narraciones de las novelas, la metodología que a la geografía le hacia falta. Covarrubias parecía encarnar, en el siglo xx, al artista que la disciplina extrañaba y del cual encontraba su referencia en otros artistas viajeros, como Humboldt. Pero, en el caso de Leighly, las reflexiones no se detenían en el papel del geógrafo como artista o en la capacidad de observación que éste debería de tener. Para poder responder a una de las preguntas recurrentes de la geografía cultural (¿por qué esta forma está presente y cómo se relaciona con otras formas?), Leighly encontró que las propias obras de arte, objetos de la cultura material creados por los pueblos que se estudiaban, servirían como una fuente particularmente expresiva.

Así, tituló Leighly a la siguiente sección de su texto, "Las obras de arte en el paisaje cultural" en donde reconoce que el interés por los fenómenos culturales no era nuevo y que mucho de lo que los geógrafos estaban aprendiendo venía de los antropólogos. Sobre todo, los geógrafos aprendían, de estos últimos, que la cultura tenía una dimensión temporal además de una espacial, y que la primera era incluso más importante. ${ }^{20}$ Entonces, era necesario que se entendieran históricamente los elementos culturales del paisaje. Pero ¿qué pasaba cuando se intentaba hacer la historia de aquellos pueblos que no contaban con documentos históricos que permitieran esta investigación, como era el caso de la mayoría de los pueblos indígenas? El geógrafo tenía entonces que recurrir a la historia del arte e investigar los productos materiales de la creación artística.

A esta propuesta metodológica Leighly la llamó una topografía del arte y se vuelve particularmente importante para entender el mapa Art forms of the Pacific Area (fig. 5). Éste es quizá, dentro de la serie, el mapa en donde Covarrubias pudo desplegar con mayor libertad el comienzo de una teoría artística de los

from science. Artistic cults there may be, and artistic techniques drawn from science. But these relations to cult and science are inessential: the artist's work remains the communication through technical skill of arbitrarily selected and subjectively perceived experience. In the present state of science, and in any future state that may de expected to grow out of its present state, the scientist must proceed by analysis, and his insight is the more profound the more thorough his analysis. The artist is the synthesist of phenomena; so far as we can see, the only who can join intellectual incommensurables to form a comprehensible and satisfying conceptual whole", en Leighly, "Some Comments in Contemporary Geographic Method", I32-I35.

20. Véase Carl O. Sauer, "The Fourth Dimension of Geography", Annals of the Association of American Geographers 64, núm. 2 (junio de 1974): 189-192. 
objetos indígenas de la cuenca de Pacífico. En él, el artista hizo una selección de objetos, etnográficos y arqueológicos por igual, que le permitieron dibujar sobre los territorios representados el flujo de un estilo artístico que se propondría relacionar a una buena cantidad de objetos entre sí. Al retomar un término tan propio de la geografía —el de la topografía—, se observaría mejor cómo Covarrubias intentaba dar cuenta de la manera en que una forma artística había logrado asentarse sobre un territorio a lo largo del tiempo. Si se estudia no sólo la forma evidente y más reciente, sino las capas que se encuentran enterradas y que permiten que una forma se vuelva significativa para la cultura que la creó, es posible comprender por qué se consideraba que el arte era capaz de otorgarle al paisaje cultural un carácter que lo distinguiera de otros.

\section{Deseo estético/deseo afectivo}

Muchas veces se ha seńalado la influencia de Franz Boas en el trabajo de Miguel Covarrubias. Pero, me gustaría enfocarme en un principio de la teoría de Boas del que el artista se iría distanciando conforme conociera y pensara en otras posibilidades para la teoría geográfica y su relación con los objetos artísticos. Al igual que Covarrubias, Boas creía que era posible aplicar un método geográfico para analizar la difusión de un estilo artístico en aquellos casos en los que la evidencia arqueológica o histórica no fuera suficiente, como sucedía con la mayoría de los objetos de las culturas indígenas. Sin embargo, para asegurar que efectivamente se trataba de una difusión, Boas exigía que: "en la reconstrucción de un desarrollo histórico, una prueba de la conexiones históricas de las formas culturales en áreas distintas debe de estar basada en el acontecimiento de fenómenos complejos y en la distribución de estos fenómenos a lo largo de áreas continuas." ${ }^{21}$

Me gustaría recuperar una faceta tal vez menos conocida de Franz Boas, quien antes de convertirse en uno de los antropólogos más importantes del siglo $\mathrm{xx}$, se formó como un geógrafo que prestó especial atención a las regiones del Pacífico. Como lo describe David Dinwoodie, en una serie de ensayos

2I. "For this reason we demand in a reconstruction of historic development that a proof of historical connection of cultural forms in distinct areas should be based on the occurrence of complex and unrelated phenomena and upon the distribution of the phenomena and upon the distribution of the phenomena over continuous areas", en Franz Boas, "Anthropology", en Enciclopedia of Social Science, ed. Edwin R. A. Seligman (Nueva York: The Macmillan Company, 1930), 74. 


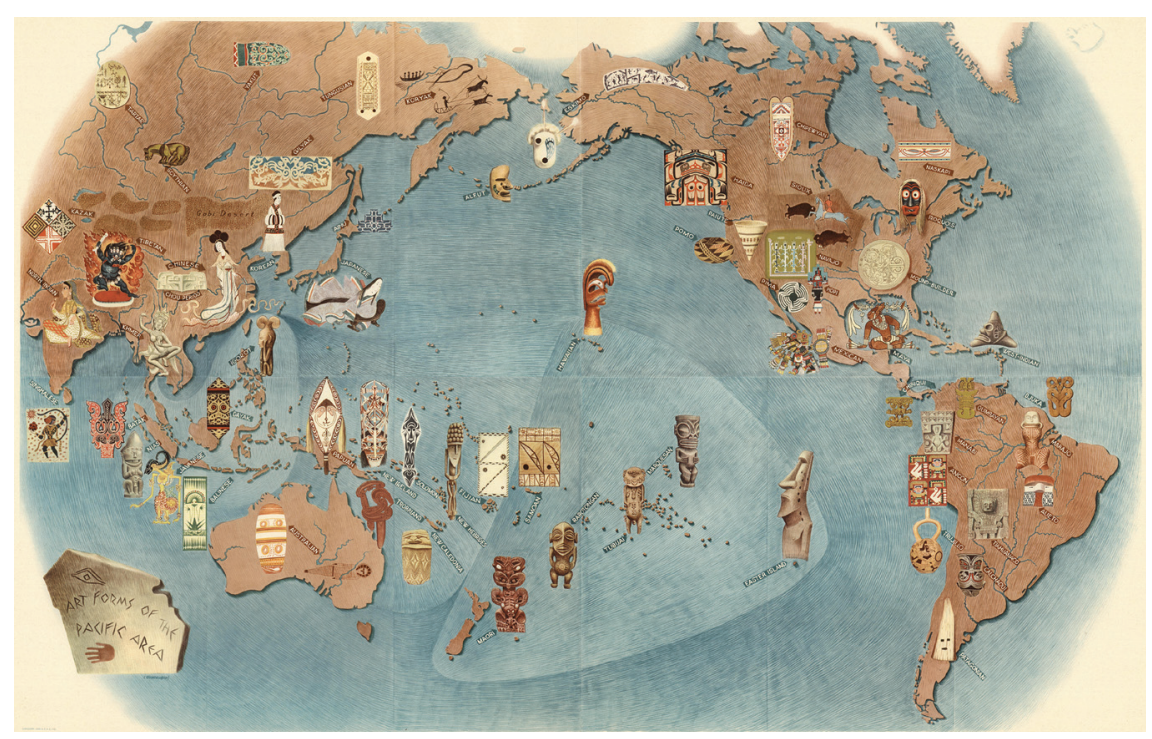

5. Miguel Covarrubias, Art Forms of the Pacific Area, 1939. Treasure Island Development Authority.

publicados recientemente acerca de su obra, a finales del siglo XIX éste sufrió una crisis intelectual que se derivó del estudio que realizó acerca de algunas poblaciones de esquimales. Boas consideró que era necesario cambiar el enfoque de la geografía de un científico a un campo totalmente histórico. En palabras de Dinwoodie: "Boas reunió evidencia para demostrar que los habitantes de la cuenca del Pacífico no podían ser estudiados efectivamente de acuerdo con presupuestos burdos acerca de las relaciones raciales entre americanos y asiáticos, y tampoco basados en una explicación única de un gran sistema de la evolución de las sociedades." 22

De esta manera Boas se posicionaba en contra de ciertas nociones positivistas que creían que los fenómenos individuales eran significativos solamente si eran emanaciones de una ley general. En un texto de 1887, The Study of

22. "He marshaled evidence to demonstrate the peoples of the Pacific Rim could not be studied effectively in accordance with crude assumptions regarding Asian versus American races, nor on the basis of any single grand system of evolution of society", en David W. Dinwoodie, "Anthropological Activism and Boas's Pacific Northwest Etnology", en The Franz Boas Papers, vol. I (Nebraska: University of Nebraska Press, 2015). 
Geography, Boas expone los dos argumentos entre los cuales se estarían debatiendo los objetivos de la geografía a finales del siglo xix. Por un lado estaban aquellos que defendían que la geografía se debería de ocupar en deducir leyes generales y, por el otro, aquellos que abogaban por el estudio de fenómenos concretos. Boas se inclinaba por esta última posición y para hacerlo retomó la paradigmática obra de Humboldt, Kosmos. De esta obra recuperó el concepto de cosmografía como un término más adecuado para referirse a los estudios de la geografía: "Cosmografía, como podríamos llamar a esta ciencia, considera a cada fenómeno, como suficientemente valioso para ser estudiado en sí mismo", ${ }^{23}$ y unos párrafos más adelante confirma que: "Mientras que las ciencias físicas surgen de las demandas lógicas y estéticas de la mente humana, la cosmografía tiene su origen en el sentimiento personal y subjetivo del hombre acerca de su mundo, y acerca de los fenómenos que lo rodean." ${ }^{24}$

Según la postura de Boas, esas dos visiones opuestas de la geografía responden a la manifestación de dos diferentes deseos en la mente humana. Por un lado, el deseo estético que obedece a la necesidad de poner orden en el caos que se observa. Para esta ciencia, que Boas define como objetiva, el estudio de los fenómenos individuales no es importante porque no satisface el deseo estético de encontrar una lógica y un arreglo entre la confusión. Por otra parte, el deseo afectivo, al que reaccionan los cosmógrafos, y que se enfoca en los sentimientos personales del hombre hacia el mundo que habita. El placer que los primeros encontrarían en el arreglo del caos, el cosmógrafo lo encontraría en la afección positiva que le provocaba detenerse y profundizar en un fenómeno que le interesaba.

Para poner en práctica sus inquietudes cosmográficas, en el otoño de 1885 , una vez instalado definitivamente en los Estados Unidos, Boas planeó un viaje de investigación a la Columbia Británica. Su propósito era hacer un mapa de la distribución de los grupos indígenas basado en el lenguaje y el estudio de los mitos. Después de esta primera incursión realizaría al menos ocho viajes más. The Jesup North Pacific Expedition, patrocinada por el Museo de Historia Natural de Nueva York, fue probablemente una de las misiones más destacadas de Boas

23. "Cosmography, as we may call this science, considers every phenomenon as worthy of being studied for its own sake", en Franz Boas, “The Study of Geography," Science 9, núm. 210 (II de febrero de I887): I38.

24. "While physical science arises from the logical and aesthetical demands of the human mind, cosmography has its source in the personal feeling of man towards the world, towards the phenomena surrounding him", en Boas, "The Study of Geography", I39. 


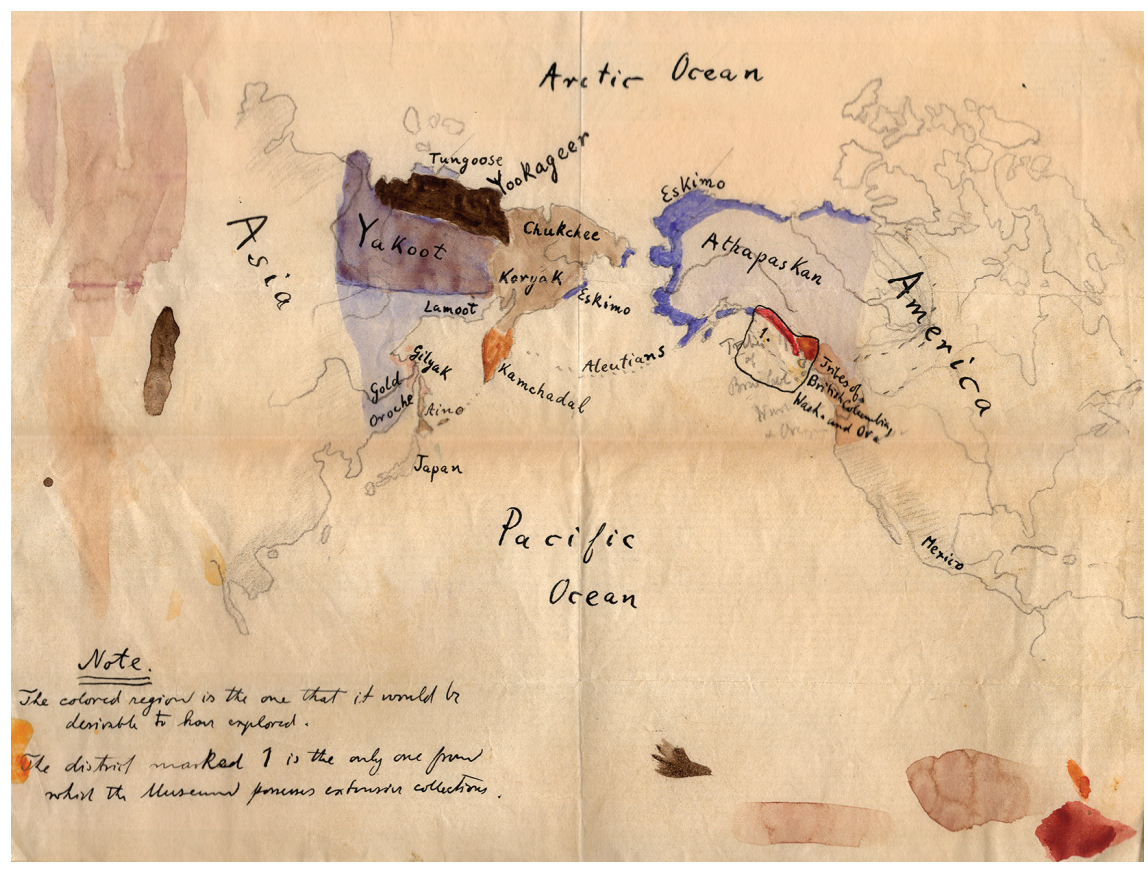

6. Franz Boas, Hand-Colored Culture Distribution Map, I896 (?). No. Catálogo: Z/ı7I. Courtesy of the Division of Anthropology. American Museum of Natural History.

y dio origen a sus teorías más conocidas y a las colecciones que desde esa fecha se han resguardado y expuesto en una de las salas más importantes del museo.

En este contexto es importante mencionar el descubrimiento, casi fortuito, de un mapa delineado y pintado a mano por Boas (utilizando lápiz y acuarela) para el proyecto de la Jesup North Pacific Expedition (fig. 6). Así como en el mapa de Covarrubias, en el de Boas el océano es el centro de la proyección y se distinguen algunas regiones ocupadas por pueblos indígenas que, como lo anota Boas en la parte inferior izquierda, son las que le gustaría explorar. El área delimitada por una línea negra y marcada con el número I, corresponde a la región de la cual el museo ya tenía objetos que formaban parte de su colección. El área ilustrada en el mapa es particularmente interesante porque representaba el probable lugar de contacto entre el Viejo y el Nuevo Mundo. A finales del siglo XIX todavía no se tenía certeza de que hubiera existido este intercambio en épocas antiguas, debido a las grandes distancias que separaban a los terri- 
torios. Sin embargo, en ese momento comenzaban a plantearse los problemas acerca de las conexiones transpacíficas que ocuparían durante muchas décadas a los antropólogos; cuestiones que abordó Miguel Covarrubias y que determinaron su trabajo una vez que se convenciera de la posibilidad de las teorías difusionistas. En palabras de Boas:

Si el desarrollo de la cultura del Nuevo Mundo no ha sido independiente de los avances hechos en el Viejo Mundo, su cultura sería de un gran valor para fines comparativos. Por lo tanto, es necesario investigar con profundidad todas las líneas y áreas posibles de contacto y, entre ellas, la costa Norte del Pacífico es probablemente la más importante. ${ }^{25}$

$\mathrm{Al}$ establecer una comparación entre los mapas de Covarrubias y Boas es importante destacar que si bien ambos colocan al océano Pacífico en el centro y sirvieron para explorar la posibilidad del contacto entre América y Asia, cada uno respondía a tendencias opuestas en el estudio de la geografía, según lo expuesto por Boas en su ensayo de 1887. Asimismo, no puede decirse que el trabajo de Covarrubias se suscribía a una tendencia positivista, aunque es verdad que la manera de abordar el problema de las coincidencias formales entre los motivos del arte indígena estaría más cercana a la tendencia del deseo estético de encontrar el orden en el caos de la multiplicidad de formas de la cuenca del Pacífico. Sin embargo, a pesar de que la obra de Covarrubias tenía una intención generalizadora, la mejor forma para expresar sus teorías fue por medio del arte, como es evidente en el caso del mapa del Pacífico. En este contexto, un último hecho resulta interesante; para Boas, la cosmografía, al querer satisfacer el deseo afectivo, estaría fuertemente vinculada con las artes: "el geógrafo, al tratar estos temas, se aproxima al terreno del arte. Como el resultado de sus estudios afectan principalmente a los sentimientos, éstos deben de ser descritos de una manera artística, para satisfacer el sentimiento que los originó."26

25. "If the development of culture in the New World has been quite independent of the advances made in the Old World, its culture will be of the greatest value for purposes of comparison. Therefore it is necessary to investigate with thoroughness all possible lines and area contact, and among these the North Pacific coast is probably the most important", en Franz Boas, "Introduction", Memoirs of the American Museum of Natural History II (I898): 5 .

26. "The geographer, in treating these subjects, approaches the domain of art, as the results of his study principally affect the feeling, and therefore must be described in an artistic way in order to satisfy the feeling in which it originated", en Boas, “The Study of Geography”, I4I. 
Al tomar en cuenta esta afirmación resulta difícil decidir tajantemente a qué tendencia se suscribiría el mapa de Covarrubias.

\section{La cultura como dinámica}

Como se ha descrito, los mapas del Pacífico de Covarrubias se inscriben en el marco de la redefinición de las disciplinas de la antropología, la geografía y los estudios sobre arte indígena. Desde finales del siglo xix el paradigma con el que éstos eran abordados comenzó a cuestionarse. La estrecha relación en el desarrollo de la antropología y la historia del arte, en su periodo formativo, ha sido objeto de bastantes reflexiones. Sin embargo, creo que el vínculo entre la antropología y la geografía, y lo que esto implicó para los estudios del arte, han sido mucho menos estudiados.

En un artículo de 1967 , realizado por Marvin W. Mikesell —quien también obtuvo su doctorado en Berkeley bajo la supervisión de Carl O. Sauer-, el geógrafo reflexiona acerca de la manera en que, a pesar de que no han sido suficientemente reconocidos, los estudios de los antropólogos y los geógrafos, en especial en Estados Unidos, han estado con frecuencia relacionados. ${ }^{27}$ Mikesell sostiene que ambas disciplinas tuvieron un origen común pero que se distanciaron a lo largo del siglo xx, con la progresiva división de los departamentos en las universidades. No obstante, considera que esta separación es "más arbitraria que lógica", ${ }^{28}$ porque ambas estarían respondiendo a un concepto de cultura común, que requiere para su investigación de estudios interdisciplinarios: "Sin embargo, la separación parece menos empática cuando uno examina el trabajo sustantivo, porque aquellos académicos preocupados con el mundo real tienden a ignorar los límites." 29

27. Mikesell señala que fue precisamente Sauer, en el ensayo de 1925, The Morphology of Landscape, quien sugirió que la unión de la antropología y la geografía permitiría crear gradualmente una gran ciencia del hombre. Véase Marvin W. Mikesell, "Geographic Perspectives in Anthropology", Annals of the Association of American Geographers 57, núm. 3 (1967): 617-634.

28. "More arbitrary than logical", en Marvin W. Mikesell, "Geographic Perspectives in Anthropology," Annals of the Association of American Geographers 57, núm. 3 (1967): 634.

29. "However, the separation seems less emphatic when one examines substantive work, for scholars concerned with the real world have tended to ignore boundaries", en Mikesell, "Geographic Perspectives in Anthropology", 634 . 
El trabajo cartográfico de Covarrubias se encuentra directamente involucrado en este ámbito, en el que la creación de mapas y su uso para los estudios de la distribución de los rasgos culturales eran relevantes para los antropólogos y necesarios para los geógrafos. Mikesell apunta, por ejemplo, que el desarrollo del concepto de áreas culturales sería uno de los casos en los que ambas disciplinas establecerían un diálogo cercano:

Los antropólogos nunca han sido indiferentes al problema de la clasificación por áreas, tan sólo porque los artefactos en las colecciones de los museos requieren esa etiqueta. En efecto, el primer esfuerzo para clasificar las áreas culturales de los indios nativos de Norteamérica fue emprendido por Wissler como consecuencia de sus labores en el Museo de Historia Natural. ${ }^{30}$

Tanto el uso de mapas como del concepto de área cultural se convirtieron en un instrumento esencial para clasificar cartográficamente a los grupos indígenas de Norte, Centro y Sudamérica. Como ya se mencionó, estas herramientas surgieron a la par del desarrollo de las colecciones de los Museos de Historia Natural, pero también se utilizaron en las exposiciones de los museos de arte. René D'Harnoncourt —al menos desde la exposición Indian Art of the United States and Alaska montada en 1939 en el edificio federal de la Golden Gate International Expedition- solía incluir en las primeras salas de sus exposiciones mapas en donde se clasificaban, según criterios diversos, los objetos de las culturas que se presentaban en las salas.

Además, el difusionismo — que unos años después defendería Covarrubias-, se relacionó cercanamente con la formulación del concepto de las áreas culturales. Alfred L. Kroeber fue uno de los principales antropólogos que desarrolló este concepto como producto de su experiencia de trabajo con Boas y, en especial, por su convivencia con los geógrafos de la Universidad de Berkeley. La finalidad de Kroeber era estudiar cómo se llevaban a cabo las relaciones entre distintas áreas culturales y así entender el desarrollo general de algún proceso cultural. Sin embargo, al igual que Covarrubias, Kroeber reflexionó

30. "Anthropologists have never been indifferent to the problem of areal classification, if only because the artifacts in museum collections require such label. Indeed, the first serious effort to classify the culture areas of native North America was undertaken by Wissler as a consequence of his duties at the American Museum of Natural History", en Mikesell, "Geographic Perspectives in Anthropology", 62I. 
acerca de la dificultad que implica delimitar fronteras estáticas en un mapa de áreas culturales:

Sería deseable entonces construir mapas culturales sin líneas divisorias (o fronterizas), con un sistema de sombreado o variaciones en el tinte del color. Pero las dificultades mecánicas para lograr esto son grandes. Por el momento, parece necesario usar los viejos dispositivos y dejar que sea el lector el que traduzca lo que sus ojos ven y que lo transforme en los aspectos dinámicos que se pretende mostrar. Esta dificultad es inherente a todos los intentos por expresar en un espacio estático bidimensional, un fenómeno que tienen aspectos tanto secuenciales como espaciales; un flujo así

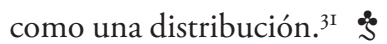

3I. "It would be desirable, therefore, to construct cultural maps without boundaries lines, on some system of shading or tint variation of color; but the mechanical difficulties are great. For the present, it seems necessary to use the old devices and leave it to the reader to translate what his eyes sees into the dynamic aspects that are intended. This difficulty inheres in all attempts to express in static two-dimensional space terms, phenomena that have a sequential as well as a patial aspect; a flow as well as a distribution", en Alfred L. Kroeber, Cultural and Natural Areas of Native North America (Berkeley: University of California Press, 1953), 6. 